\title{
Dynamics of hyaluronan, CD44, and inflammatory cells in the rat kidney after ischemia/reperfusion injury
}

\author{
ANNE-EMILIE DECLÈVES ${ }^{1}$, NATHALIE CARON ${ }^{2}$, DENIS NONCLERCQ ${ }^{3}$, \\ ALEXANDRE LEGRAND $^{2}$, GÉRARD TOUBEAU ${ }^{3}$, RONALD KRAMP ${ }^{2}$ and BRUNO FLAMION ${ }^{1}$ \\ ${ }^{1}$ Molecular Physiology Research Unit (URPHYM), Laboratory of Physiology and Pharmacology, \\ FUNDP - University of Namur, 61 rue de Bruxelles, B-5000 Namur; Departments of ${ }^{2}$ Physiology and \\ Pharmacology, ${ }^{3}$ Histology, University of Mons-Hainaut, 6, avenue du Champ de Mars, B-7000 Mons, Belgium
}

Received February 6, 2006; Accepted March 30, 2006

\begin{abstract}
Ischemia/reperfusion (I/R) injury in the kidney involves hemodynamic and cellular dysfunctions as well as leukocyte infiltration. Functional recovery occurs via cell proliferation and/or migration. To determine the roles of hyaluronan (HA) and its main receptor CD44 in renal postischemic processes, we compared their localization and expression with that of neutrophils, macrophages, and PCNApositive (regenerative) cells as characterized by immunohistochemistry, up to 28 days after I/R in uninephrectomized rats. Observations covered all kidney zones, i.e. cortex (C), outer and inner stripes of outer medulla (OSOM, ISOM), and inner medulla (IM). In controls, HA was localized to the interstitium of IM and ISOM, and CD44 was mostly present on the basolateral membranes of collecting ducts in ISOM, the thin descending limb of Henle's loop and macula densa cells. After I/R, HA and CD44 staining appeared in C and OSOM at $12 \mathrm{~h}$ and persisted throughout the regenerative period, i.e. until day 7 . Thereafter, they regressed but remained associated with remodeling areas. CD44 expression was found de novo on the apical pole of regenerating, not fully differentiated tubular cells and on some interstitial cells. It was prominent on all infiltrating neutrophils, as soon as $2 \mathrm{~h}$ post$\mathrm{I} / \mathrm{R}$, and on $30 \%$ of the macrophages, including those in late HA-rich inflammatory granulomas. CD44 is probably involved in early leukocyte infiltration, in tubular regeneration, and in macrophage activity, while HA modifies the physico-chemical environment of interstitial and migrating cells. Based on its
\end{abstract}

Correspondence to: Dr Bruno Flamion, Molecular Physiology Research Unit (URPHYM), Laboratory of Physiology and Pharmacology, FUNDP - University of Namur, 61 rue de Bruxelles, B-5000 Namur, Belgium

E-mail: bruno.flamion@fundp.ac.be

Key words: hyaluronic acid, acute renal failure, matrix, immunohistochemistry presence in remodeling areas, the HA-CD44 pair may be implicated in persistent postichemic inflammation as observed in chronic allograft nephropathy.

\section{Introduction}

Acute renal failure remains associated with high morbidity and mortality rates in humans. It may result from ischemic insult to the kidney followed by reperfusion, i.e. ischemiareperfusion (I/R) injury. I/R injury is a prominent negative factor in the survival of renal allografts (1). The pathophysiology of I/R damage includes cellular hypoxia, tubular and endothelial injuries, sustained vasoconstriction, and leukocyte infiltration (2). The pathophysiological relevance of renal inflammation in the course of ischemic injuries is supported by evidence of the commonly protective effects of neutrophil depletion, blockade of neutrophil adhesion, or deficiencies in $\mathrm{T}$ cells $(3,4)$. Recovery and repair of severe renal I/R injury are often incomplete and permanent damage to peritubulular capillaries, chronic hypoxia, and progressive fibrosis have been observed several weeks after the injury $(5,6)$. The extent of residual damage is dependent on the severity of the insult as well as on renal mass, since renal structure 20-30 weeks after I/R is more severely disrupted in rats with a solitary kidney, despite a similar degree of acute renal failure (7).

Among the other factors potentially involved in the processes of inflammation and regeneration of the postischemic renal tissue are hyaluronan (HA) and its main receptor CD44. $\mathrm{HA}$ is a ubiquitous glycosaminoglycan found in the extracellular matrix of many tissues including the renal medulla, but not the cortex. It has been shown to accumulate in the cortex in several kidney diseases, including crescentic glomerulonephritis (8), ethylene glycol intoxication (9), allograft rejection (10), and I/R injury (11), but its precise cellular localization and time course of appearance in both the cortex and the outer medulla are not clearly defined. Similarly, the adhesion receptor CD44 is strongly upregulated on proximal tubule cells during toxic, immunologic or $\mathrm{I} / \mathrm{R}$ insults $(8,9,12)$. Activation of the HA-CD44 pair within damaged tissues may be part of the inflammatory process (13) but it may also help the regenerative and healing processes, as illustrated by 
delayed resolution of inflammation and reduced HA clearance in CD44-knockout mice suffering renal, liver or lung injuries $(12,14,15)$.

An important aspect of tubular lesions and regeneration in $\mathrm{I} / \mathrm{R}$ injury is their uneven distribution in the kidney, with the outer medulla and particularly the S3 segment of the proximal tubule being most affected (16). Similarly, inflammatory cell infiltration follows precise spatial and temporal patterns $(17,18)$. However, regarding the contribution of HA and CD44 to postischemic processes, their precise timing of apparition and waning, their exact distribution amongst the different renal zones, and their possible association with tubular damage, inflammatory infiltration and/or regeneration processes remain unknown. Therefore, to elucidate the roles of HA and CD44 in postischemic processes, we studied their cellular and extracellular localizations and expressions in the cortex and medulla at various time points following I/R injury. An immunohistochemical approach was used in an experimental rat model of acute I/R injury in a single kidney. This model mimics severe warm ischemia in a renal allograft. The presence of neutrophils and monocytes/macrophages was assessed in parallel with the other histological measurements. Our analysis was not restricted to the early events in the cortex but was extended to the deeper zones, i.e. outer and inner stripes of the outer medulla (OSOM, ISOM), and inner medulla (IM), and covered a prolonged time course of up to 28 days.

\section{Materials and methods}

Animals and treatment. The study conformed to APS's guiding principles in the Care and Use of Animals and was approved by the 'Comité d'Ethique Animale' of the 'Université de MonsHainaut'. Experiments were performed on male Wistar rats weighing 220-260 g. The animals were bred and maintained in our animal facility accredited by the Belgian Ministry of Middle Class and Agriculture. Animals were submitted to different pre-treatments before euthanasia and analysis of kidney morphology. They were randomly distributed into three groups: 1) Control: both kidneys removed without pretreatment $(\mathrm{n}=6)$; 2) Sham: pre-treatment consisting in a right nephrectomy $(\mathrm{n}=20)$; 3$) \mathrm{I} / \mathrm{R}$ : animals submitted to a left renal ischemia before the right nephrectomy $(n=42)$.

Treated animals were anaesthetized with sodium pentobarbital (Nembutal, $60 \mathrm{mg} \mathrm{kg}{ }^{-1}$ body weight, injected intraperitoneally; Ceva Santé animale, Brussels, Belgium), and after completion of anaesthesia, were placed on a heated table to maintain body temperature between 37 and $38^{\circ} \mathrm{C}$. The left kidney was exposed through a midline abdominal incision and the renal vascular pedicle was gently dissected from surrounding tissues. When appropriate, the left renal artery was clamped with a microvascular clamp (Fine Science Tools, Heidelberg, Germany) for $60 \mathrm{~min}$. The kidney was carefully inspected for optimal reperfusion before removal of the right kidney.

After the surgical preparation, the animals were allowed to recover in separate cages and were weighed and inspected daily to evaluate their health status. Euthanasia was performed at the following hours after reperfusion of the left kidney: 2, 12, 24, 48, 168 (7 days), 336 (14 days) and 672 (28 days). For the three groups, removal of the kidney was performed immediately after the euthanasia and blood samples were collected by aortic puncture.

Analytical methods. Blood sample was centrifuged at high speed for $20 \mathrm{~min}$ at $4^{\circ} \mathrm{C}$. Plasma was collected and frozen at $-20^{\circ} \mathrm{C}$ until use. Plasma creatinine concentration was determined using a colorimetric method to evaluate renal function.

Immunohistochemical methods. After removal, the left kidney was decapsulated, blotted dry, weighed and bisected. Renal tissue was first immersed in Duboscq-Brazil fluid (formalin/ acetic acid/ethanol containing $1 \%$ picric acid/water, 260:70:425:245 volume ratio) for $48 \mathrm{~h}$ at room temperature. The fixed samples were thereafter rinsed in $70^{\circ}$ ethanol, progressively dehydrated in graded ethanols and in butanol, and embedded in Paraplast Plus ${ }^{\circledR}$ paraffin according to standard procedures. Paraffin sections of 4-5 $\mu \mathrm{m}$ thickness were cut on a Reichert Autocut 2040 microtome (Reichert Jung, Nossloch, Germany) and mounted on silane-coated glass slides. Immunohistochemical detection of CD44, Aquaporin-3 (AQP-3), PCNA (proliferation cell nuclei antigen) and monocytes/macrophages was performed using the following method. After dewaxing and rehydratation, antigens present in the renal tissue were unmasked by microwave pre-treatment in $0.01 \mathrm{M}$ citrate buffer ( $\mathrm{pH} 6.2$ ) $2 \times 5 \mathrm{~min}$ at a power of $900 \mathrm{~W}$. After cooling, these sections were incubated for $5 \mathrm{~min}$ in $0.06 \%$ $\mathrm{H}_{2} \mathrm{O}_{2}$ in water to quench any endogenous peroxidase activity. After rinsing in distilled water and in PBS buffer $(0.04 \mathrm{~mol} / \mathrm{l}$ $\mathrm{Na}_{2} \mathrm{HPO}_{4}, 0.01 \mathrm{~mol} / 1 \mathrm{KH}_{2} \mathrm{PO}_{4}$, and $0.12 \mathrm{~mol} / \mathrm{l} \mathrm{NaCl}, \mathrm{pH} 7.4$ ), the sections were incubated for $15 \mathrm{~min}$ with solutions containing avidin and biotin (Vector Laboratories, Burlingame, CA, USA), respectively. Then, the sections were rinsed in PBS and pre-incubated with $0.5 \%$ casein for $15 \mathrm{~min}$. Without rinsing, the slides were incubated for $1 \mathrm{~h}$ with different primary monoclonal or polyclonal antibodies: 1) anti-CD44 (mouse anti-rat monoclonal antibody OX49, Pharmingen, San Diego, CA, USA), 1:50; 2) anti-PCNA (mouse anti-rat monoclonal antibody PC10, Dako, Denmark), 1:50; 3) anti-monocytes/ macrophages (mouse anti-rat monoclonal antibody ED-1, Serotec, Oxford, UK), 1:75; 4) anti-AQP3 (rabbit anti-rat polyclonal antibody LL178AP, kindly provided by Dr S. Nielsen, Water and Salt Research Center, University of Aarhus, Denmark), 1:100.

After rinsing in PBS, the slides were exposed for $30 \mathrm{~min}$ to a secondary antibody: biotinylated goat anti-mouse $\mathrm{IgG}$ (Dako) for CD44 and PCNA and a swine anti-rabbit IgG (Dako) for anti-AQP3, respectively. Kidney sections were finally incubated with ABC complex (Dako) for $30 \mathrm{~min}$. Bound peroxidase activity was detected by the precipitation of 3,3'-diaminobenzidine (DAB-0.02\%) in PBS containing $0.02 \% \mathrm{H}_{2} \mathrm{O}_{2}$. Finally, the sections were counterstained with periodic acid-Schiff, hemalun, and Luxol fast blue to allow the identification of histological structures. Detection of HA was performed using a biotinylated HA-binding protein (HABP, Sigma-Aldrich, St. Louis, MO, USA). The procedure of dewaxing and rehydratation as well as the successive treatments with $\mathrm{H}_{2} \mathrm{O}_{2}$, avidin, biotin and casein were similar to those described above, but the microwave pre-treatment was omitted. Kidney sections were first incubated for $1 \mathrm{~h}$ with HABP. The presence of HABP was revealed by the method 
of Tyramin-Signal Amplification (TSA, Perkin Elmer, Boston, MA, USA) based on a peroxidase-catalyzed deposition of biotinylated tyramide which in turn was detected with peroxidase-streptavidin. This procedure results in a greatly amplified signal. Peroxidase activity was visualized by incubating tissue sections in the presence of $\mathrm{H}_{2} \mathrm{O}_{2}$ and DAB in PBS. Counterstaining was performed with hemalun and Luxol fast blue.

Immunofluorescent staining. The coexpression of markers (CD44 and ED-1) was analyzed by a double-label immunofluorescence method. Since all antibodies were raised in mouse, we applied a technique described in a previous publication (19) to avoid cross-reactivity between the secondary antibodies. This technique, originally developed by Lan et al (20), was based on the use of microwave heating to block secondary antibodies cross-reactivity between sequential steps of immunostaining. Prior to immunofluorescence, paraffin sections were dewaxed, rehydrated and pretreated following the protocol described above. Sections were then labelled sequentially at room temperature with the first primary monoclonal antibody (anti-ED-1) followed by a biotinylated anti-mouse $\operatorname{IgG}(1: 50)$ and finally by Texas-Redconjugated streptavidin (1:50). After these steps, the sections were exposed to microwave irradiation to denature mouse immunoglobulins. Therafter, the sections were incubated for $1 \mathrm{~h}$ at room temperature with the second primary antibody (monoclonal anti-CD44) followed by FITC-conjugated secondary antibody (1:50) for $30 \mathrm{~min}$. After final rinses in distilled water, the sections were mounted in Vectashield mounting medium (Vector Laboratories).

Histological detection of polymorphonuclear neutrophils and mast cells. Polymorphonuclear neutrophils displaying immunoreactivity to CD44 were localized on kidney sections on the basis of cytological landmarks such as typical segmented nucleus and small granules present in the cytoplasm. An intense counterstaining of nuclei by haematoxylin was applied in order to identify neutrophils without doubt. Mast cells were clearly evidenced on kidney sections after a specific histological staining with cresyl violet and picrofuchsin.

Semiquantitative assessment of histopathogical alterations. The degree of tissue injury was assessed on a semi-quantitative basis by adapting a single-blind analysis of paraffin sections (1 section per experimental animal) detailed previously (21). Slides were coded and analyzed by one of us who was kept blinded of the treatment. To standardize the evaluation procedure, an additional lens engraved with a $1-\mathrm{cm}^{2}$ square grid was inserted in one of microscope eye pieces. Each paraffin section was scanned at $\times 400$ magnification, and 20 square fields, each covering an area of $0.084 \mathrm{~mm}^{2}$, were evaluated ( 5 in each renal zone). Tissue alterations were graded along an arbitrary scale, according to the following criteria:

A) Proximal tubules: 0, no departure from normal morphology; 1, abnormal large water-filled vacuoles (hydropic degeneration), focal interruptions of brush border, or focal cell necrosis; 2 , one tubular section containing necrotic or atrophic cells; 3, 2-5 necrotic or atrophic tubular sections; 4, >5 necrotic or atrophic tubular sections.
B) Distal tubules and collecting ducts: 0, no clear-cut sign of histopathological alteration; 1 , evidence of hydropic degeneration or single-cell necrosis; 2 , only one necrotic tubular profile; 3, 2-5 necrotic tubules; 4, >5 necrotic tubules.

C) Cystic tubules: 0, absence of abnormally dilated tubule; 1 , one tubular section exhibiting epithelium flattening and a widely dilated lumen; $2,<50 \%$ of the field occupied by cystic tubules, as defined in $1 ; 3,>50 \%$ of the field covered by cystic tubules.

D) Interstitial infiltration: 0 , one or several clusters of $<5$ interstitial cells; 1 , at least one cluster of 6-25 interstitial cells; 2 , same as 1 , but $26-50$ cells visible in the interstitial area; 3 , same as 1 but $>50$ interstitial cells visible.

Morphometric analysis of marker immunoreactivity in renal tissue. The relative area occupied by HA and CD44 in renal tissue was evaluated by a computer-assisted morphometric approach. The procedure utilized a hardware consisting of a high-resolution JVC-KY15E color video camera mounted on a Zeiss Axioplan microscope and connected to an IBMcompatible microcomputer and a software specifically designed for color analysis and morphometry (KS-400 imaging system, Carlzeiss Vision GmbH, München, Germany). The sections were analyzed by scanning 5 fields at x100 magnification in cortex, OSOM, ISOM and IM. The surface of one field represents $293,000 \mu \mathrm{m}^{2}$. This image analysis system discriminates immunoreactive areas on the basis of differences of colour and contrast. For each renal zone the relative area occupied by HA and CD44 was expressed as a percentage. Individual observations were pooled for each marker and for each zone and presented in histograms as means \pm standard error of the mean (SEM).

Cell counts. The frequency of proliferating cells (labelling index) was evaluated by a semiquantitative analysis as described previously (22). Briefly, proliferating cells were detected by an immunocytochemical procedure using a monoclonal antibody directed against PCNA. The distribution of proliferating cells in the different histological structures of the renal tissue was performed on one section per experimental animal. For each section, 5 square fields $\left(0.084 \mathrm{~mm}^{2} /\right.$ field $)$ were observed at $\mathrm{x} 400$ magnification. The incidence of PCNA-positive cells was evaluated in the different tubular structures, in glomeruli, in blood vessels and in renal interstitium. Individual observations were pooled for each structure and zone and presented in histograms as means \pm SEM. The frequency of ED1-positive monocytes/macrophages was evaluated by a similar semiquantitative analysis and the relative cell density expressed per $\mathrm{mm}^{2}$ in the different renal zones. Neutrophil infiltration associated with the acute inflammatory process was observed at $\mathrm{x} 1000$. Morphometric analysis of neutrophil density was based on 20 square fields $\left(0.014 \mathrm{~mm}^{2} /\right.$ field $)$ picked at random in the 4 different renal zones as detailed before. For each renal area, individual data were pooled per experimental group and relative cell densities presented in histograms as means \pm SEM.

Calculations and statistics. Results were presented as mean values \pm SEM. The level for statistical significance was defined 

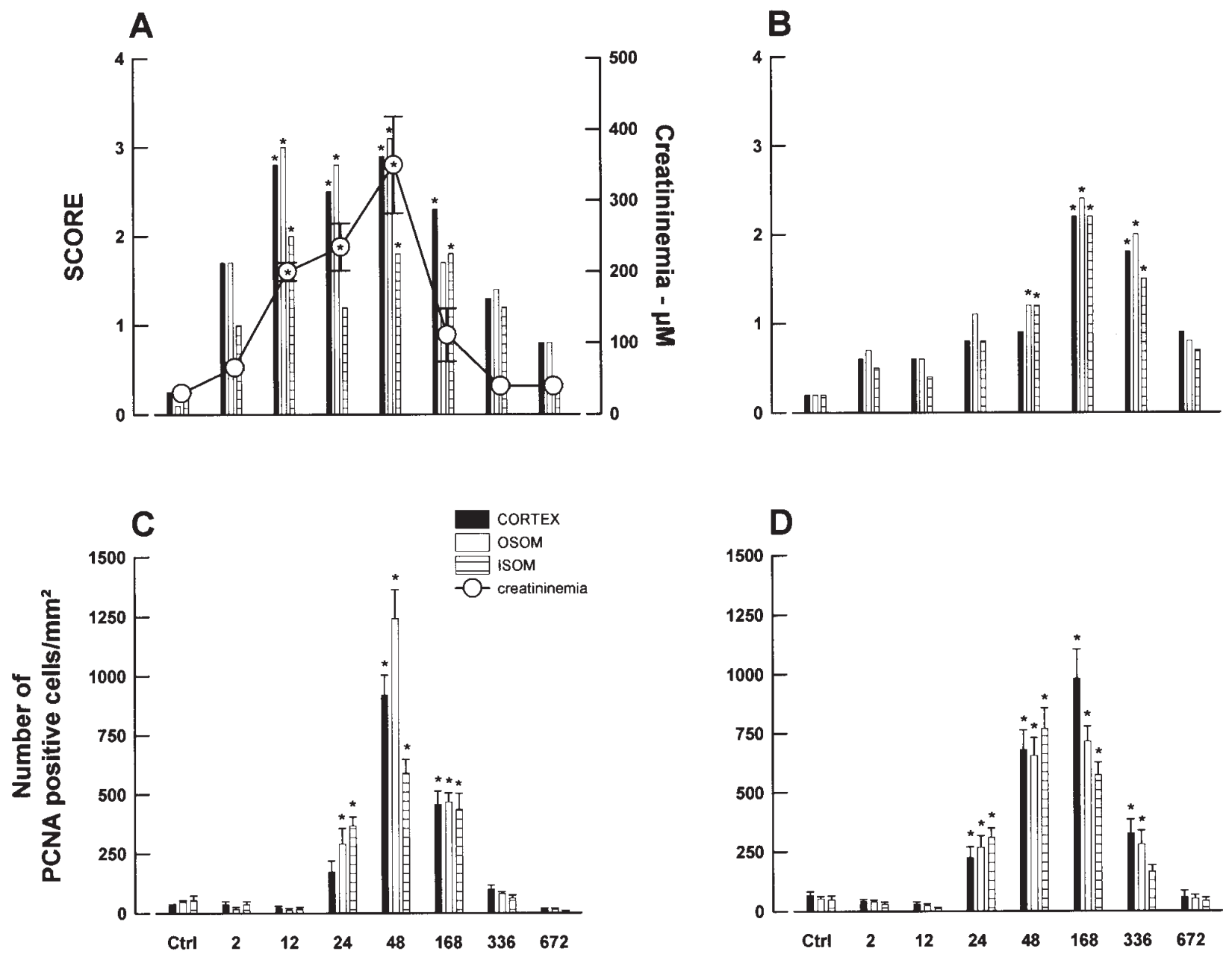

Time after I/R - hours

Figure 1. Temporal evolution of creatininemia (panel A, open circles), tubular lesions (panel A, bars), interstitial infiltration (panel B), and cellular proliferation (panel C, tubular cells, and panel D, interstitial cells) in cortex (black bars), OSOM (white bars) and ISOM (hatched bars), in controls (Ctrl) and at different time points after I/R. Statistical analysis on creatininemia and proliferation data was performed with a one-way ANOVA for multiple intergroup comparisons followed by the Dunnett's test to identify significant differences from the control group. When assessing the degree of lesions, non-parametric Kruskal-Wallis one-way ANOVA on Ranks was applied for multiple intergroup comparisons followed by the Dunn's test to identify significant differences from the control group; ${ }^{*} \mathrm{p}<0.05$.

as $\mathrm{p}<0.05$. One-way ANOVA was applied for multiple intergroup comparisons followed by the Dunnett's test to identify significant differences from the control group. When assessing the degree of tissue injury, non-parametric Kruskal-Wallis oneway ANOVA on Ranks was applied for multiple intergroup comparisons followed by the Dunn's test to identify significant differences from the control group. In postischemic lesions and proliferation, in HA and CD44 analysis, and in leukocyte localization and quantification, no difference was observed between sham and control groups. For the sake of simplicity, the comparison of $\mathrm{I} / \mathrm{R}$ groups with the control group at day 0 is the only one disclosed.

\section{Results}

General observations. Right kidney weight was similar in all groups, averaging $0.853 \pm 0.011 \mathrm{~g}(\mathrm{n}=68)$. In controls, left kidney weight did not differ significantly from its counterpart. After nephrectomy alone, a slight increase of plasma creatinine concentration was observed at 12, 24 and $336 \mathrm{~h}(46 \pm 4,48 \pm 2$ and $38 \pm 2 \mu \mathrm{M}$ versus $30 \pm 1 \mu \mathrm{M}$ in control; $\mathrm{p}<0.05)$.

In I/R groups, plasma creatinine concentration (Fig. 1A, open circles) doubled $2 \mathrm{~h}$ post-ischemia and was greatly enhanced from 12 to $48 \mathrm{~h}$, reaching $350 \pm 68 \mu \mathrm{M}(\mathrm{p}<0.05)$, i.e. a 10 -fold peak increase. Thereafter, creatinine returned progressively towards baseline levels $[40 \pm 3 \mu \mathrm{M}$ and $40 \pm 2 \mu \mathrm{M}$ at 336 and $672 \mathrm{~h}$, respectively; not significant (NS) versus control]. In contrast to control and sham groups, the weight of the postischemic left kidney progressively increased from $1.051 \pm 0.045 \mathrm{~g}$ on day 1 to $2.145 \pm 0.142 \mathrm{~g}$ on day $7(\mathrm{p}<0.05$ versus control); it remained elevated at day $28(1.460 \pm 0.150 \mathrm{~g}$, $\mathrm{p}<0.05$ versus control).

Histopathological alterations and cell proliferation. The lesions of tubular and interstitial structures consecutive to I/R were assessed on the basis of morphological criteria. As shown in Fig. 1A (bars), tubular injury was already present in cortex, OSOM, and ISOM $2 \mathrm{~h}$ after I/R. The score relative to 


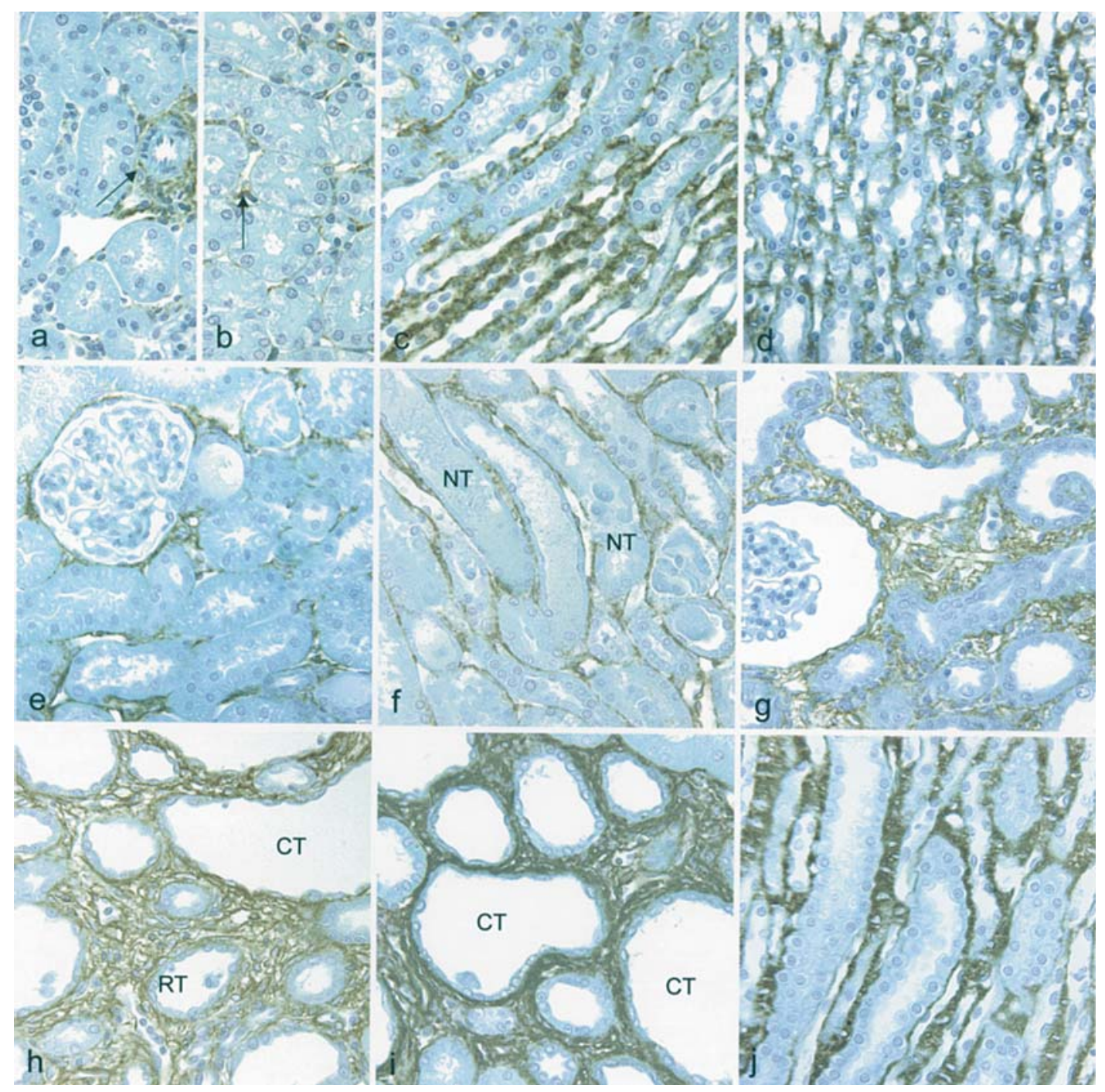

Figure 2. Distribution of HA labeling in renal tissue of control rats (a-d) and at different time points after I/R (e-j). In cortex of controls (a), labeling was restricted to the periphery of blood vessels (arrow). In the medulla, the labeling appears as a loose interstitial network in OSOM (b; arrow) while a dense HA staining was observed in the interstitium of ISOM (c) and IM (d). Twelve hours after I/R, HA appeared around necrotic tubules (NT) in the interstitium of cortex (e) and OSOM (f). At day 7 in cortex (g) and OSOM (h), the enlarged HA-filled interstitium was localized between regenerative (RT) and cystic tubules (CT). At day 28 after I/R (i), HA staining in OSOM was restricted to ill-repaired areas at the periphery of cystic tubules (CT). At day 7, interstitial HA in IM (j) appeared similar to controls. Magnifications: a, d, e-j, x255; b, c, x295.

the degree of severity of tubular lesions was maximal between 12 and $48 \mathrm{~h}(\mathrm{p}<0.05)$ and regressed thereafter. At days 7 through 28, a minor population of cystic tubes was still present in the three zones. No morphological lesions were observed in glomeruli and very few in IM at any time-point (data not shown in Fig. 1). In the interstitium, I/R injury induced a significant increase of interstitial cell density (Fig. 1B), which became most apparent after $24 \mathrm{~h}$. This process evolved to reach a maximum at days 7 and $14(\mathrm{p}<0.05)$, i.e. later than the main tubular damage.

Fig. 1C-D illustrates the amount of PCNA-positive, proliferative cells in tubules and in the interstitial space of the different kidney zones. PCNA-positive cells emerged in significant numbers in the tubules and interstitium $24 \mathrm{~h}$ postischemia $(\mathrm{p}<0.05)$, to reach a maximum value at $48 \mathrm{~h}$ and progressively returned to baseline levels at day 14 for tubules and at day 28 for the interstitium. Proliferating cells, evidenced by PCNA antibodies, were particularly abundant in regenerating tubules characterized by an undifferentiated flattened epithelium. PCNA-positive cells were also detected in blood vessels, mainly between $48 \mathrm{~h}$ and 7 days, and in glomeruli at $48 \mathrm{~h}$ (data not shown).

Localization of HA. As shown in Fig. 2a-d, HA staining in control rats was mainly localized in the interstitium of ISOM (Fig. 2c) and IM (Fig. 2d), but was almost absent from cortex and OSOM, except in focal areas such as the periphery of blood vessels (Fig. 2a, arrow) and the interstitium of OSOM (Fig. 2b, arrow).

After I/R injury (Fig. 2e-j), HA increased in the extracellular matrix of cortex (Fig. 2e) and OSOM (Fig. 2f) at $12 \mathrm{~h}$, and later progressively invaded the interstitium (Fig. 2g-h) leading to a remodelling of the interstitial tissue. The wave of HA accumulation in the interstitium was uniform and was associated to both cystic and regenerating tubules (Fig. 2h, CT and RT). Despite careful inspection, HA was not observed 


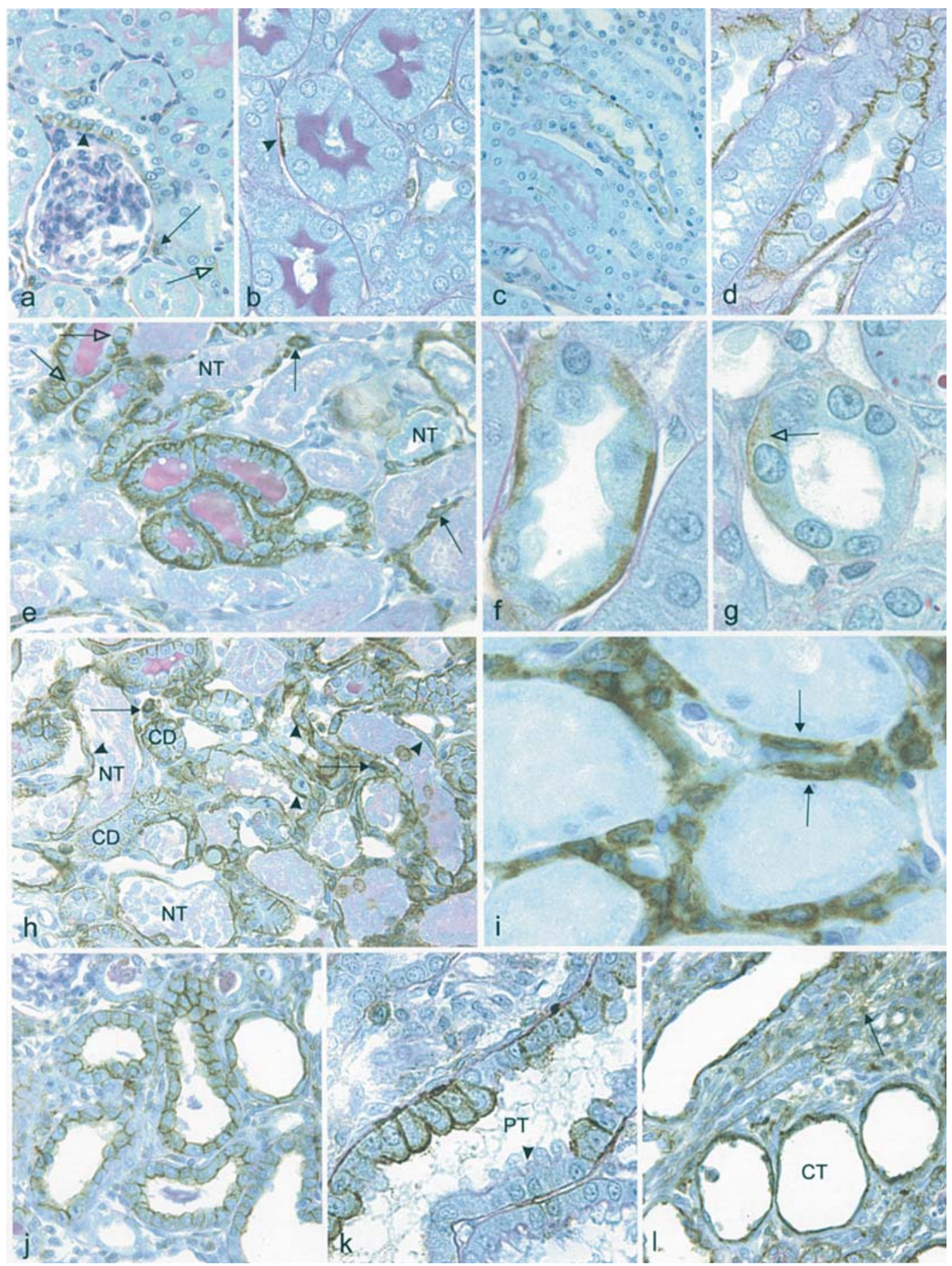

Figure 3. Immunolocalization of CD44 (a-e; h-l) and AQP-3 (f, g) in renal tissue of control rats (a-d, f) and at different time points after I/R (e, g-l). In cortex of controls (a), CD44 immunoreactivity was localized to the basal pole of collecting duct cells (open arrow), on the cells of the macula densa (arrowhead) and focally on interstitial cells (arrow). In OSOM (b), CD44 immunoreactivity was detected focally on the basal pole of isolated proximal tubular cells (arrowhead). In ISOM (c, d), CD44 immunostaining was localized to the basal pole of Henle's loop cells (c) and collecting duct cells (d). Two days after reperfusion (e), CD44 immunoreactivity was present on the basolateral membrane of collecting ducts and focally on the apical membrane (open arrows). Interstitial cells interspersed between necrotic tubules (NT) also expressed CD44 (arrows). In controls (f), AQP-3 immunostaining was associated with the basolateral membrane of collecting duct cells; two days after I/R (g), this staining was clearly reduced (open arrow). Two days after I/R (h), CD44 expression was present in flattened epithelial cells of NTs (arrowheads) and in scattered interstitial cells (arrows). In renal interstitium (i), CD44 was localized in interstitial cells such as fibroblast-like cells (arrows). At day 7 (j, k), CD44 was observed on the membrane of regenerating tubular cells but was not expressed on differentiated proximal tubular cells (k; PT) characterized by the presence of a brush border (arrowhead). One week after reperfusion (1), epithelial cells of cystic tubules (CT) and some interstitial cells (arrow) were CD44-positive. Magnifications: a, c, d, g, k, x300; b, j, x510; c, x600; e, f, x940; h, x850; i, x250.

between tubular epithelial cells. At day 28, HA significantly decreased although some persisted in remodelling zones (Fig. 2i). Interstitial HA was present at high levels in the IM throughout the postischemic observation period (Fig. 2j).
Localization of CD44. In control rats (Fig. 3a-d), CD44 immunoreactivity was present mainly on the basal membrane of collecting ducts in all zones. In ISOM, all collecting duct cells expressed CD44 at their basal pole (Fig. 3d), while in 
CORTEX
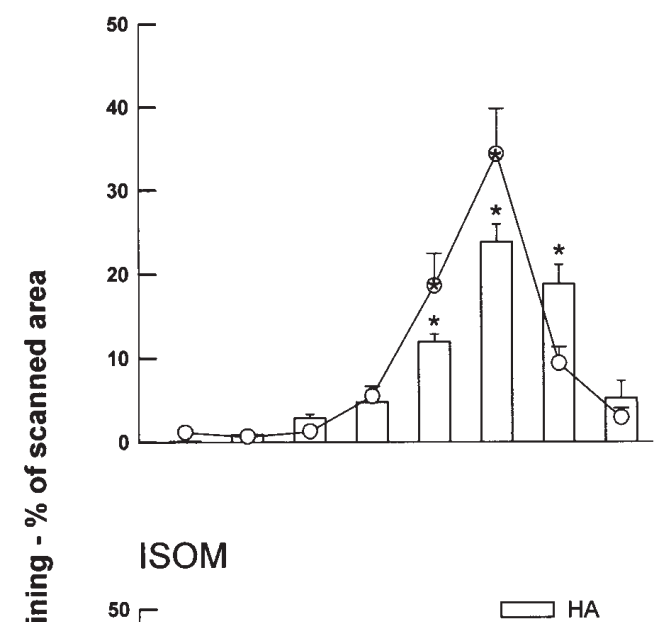

OSOM

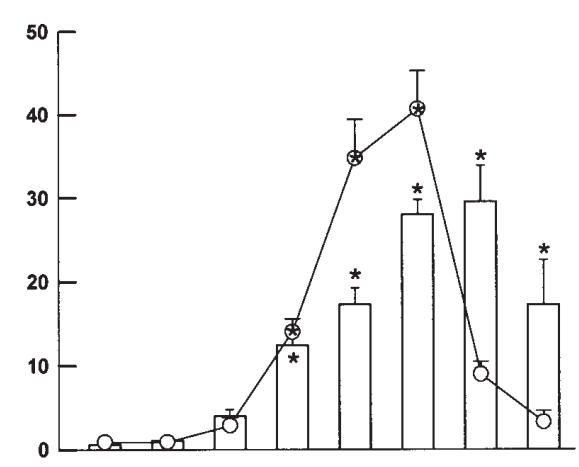

IM

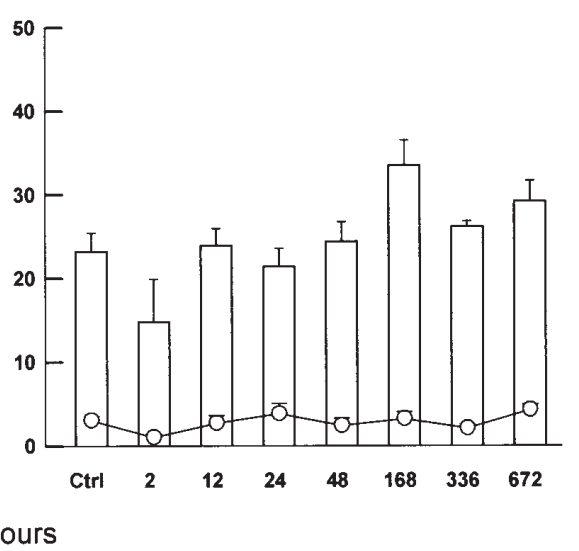

Figure 4. Temporal evolution of HA (open bars) and CD44 (open circles) immunostaining in cortex (panel A), OSOM (panel B), ISOM (panel C), and IM (panel D) in controls (Ctrl) as well as at different time-points after I/R. Statistical analysis was performed with a one-way ANOVA for multiple intergroup comparisons followed by the Dunnett's test to identify significant differences from the control group; ${ }^{*} \mathrm{p}<0.05$.

cortex and OSOM the staining was restricted to the basal pole of some cells of the collecting ducts (Fig. 3a, open arrow), irrespective of their principal or intercalated nature. The cells of the thin descending limbs of Henle's loop were uniformly positive for CD44 (Fig. 3c) and all macula densa cells expressed CD44 on their basolateral membrane (Fig. 3a, arrowhead). CD44 was also present, to a lesser extent, on isolated cells in proximal tubules (Fig. 3b, arrowhead), in a discrete population of interstitial cells (Fig. 3a, arrow), and on some glomerular cells (not shown in the figure).

After I/R, the intensity of CD44 staining in the collecting ducts increased (Fig. 3e and h) while a simultaneous decrease of AQP-3, a specific marker of the basolateral membrane, was observed (Fig. 3f and g). Furthermore, immunoreactivity for CD44 began to extend along lateral plasma membranes and crept onto apical membranes (Fig. 3e, open arrows). In cortex and OSOM, the proportion of CD44-positive cells in collecting ducts increased and CD44 immunoreactivity appeared in necrotic tubules (Fig. 3h, arrowhead, NT) where the receptor also covered the whole plasma membrane. In regenerating tubules, CD44 was detected on all cells (Fig. 3j) until they recovered normal morphological features, especially a welldefined brush border. This terminal cell differentiation process was accompanied by a complete disappearance of CD44 expression (Fig. 3k, arrowhead) suggesting that CD44 and brush border expressions were mutually exclusive. In altered tubules, CD44 expression was observed in undifferentiated proliferating cells but also in severely damaged cells located in both cystic and atrophic tubules (Fig. 31, CT for cystic tubule).

In post-I/R kidneys, CD44 staining was also observed in interstitial cells, including infiltrated leukocytes, as described in detail below, and in non-leukocytic, fibroblast-like cells (Fig. 3e, h, i, and l; arrows).

Quantification of HA and CD44 expression. Fig. 4 illustrates the time-course of HA density (bars) and CD44 immunostaining (lines) for the four renal zones following I/R injury. In cortex and OSOM, HA and CD44 evolved in parallel. The basal staining was very low in controls but increased gradually after I/R to reach a nearly 100 -fold increase on day 7 . However, CD44 returned to normal somewhat earlier than HA, especially in OSOM. ISOM of control rats contained HA, assessed to $16 \pm 2 \%$ of scanned area, and CD 44 , assessed to $5 \pm 1 \%$ of scanned area. After a transient but significant decrease in HA staining at $24 \mathrm{~h}$ post-ischemia $(6 \pm 2 \%, \mathrm{p}<0.05$ versus control), this glycosaminoglycan reoccupied the interstitial space of ISOM at increasingly high levels, showing a maximum of $33 \pm 2 \%$ of scanned area at day 7 and a persistently elevated level at day $28(25 \pm 2 \%$; $<<0.05)$. The amount of CD44 in postischemic ISOM increased until day 7 , but reached a peak level lower than in OSOM and returned to baseline earlier than HA. In controls, IM contained the highest amount of HA 

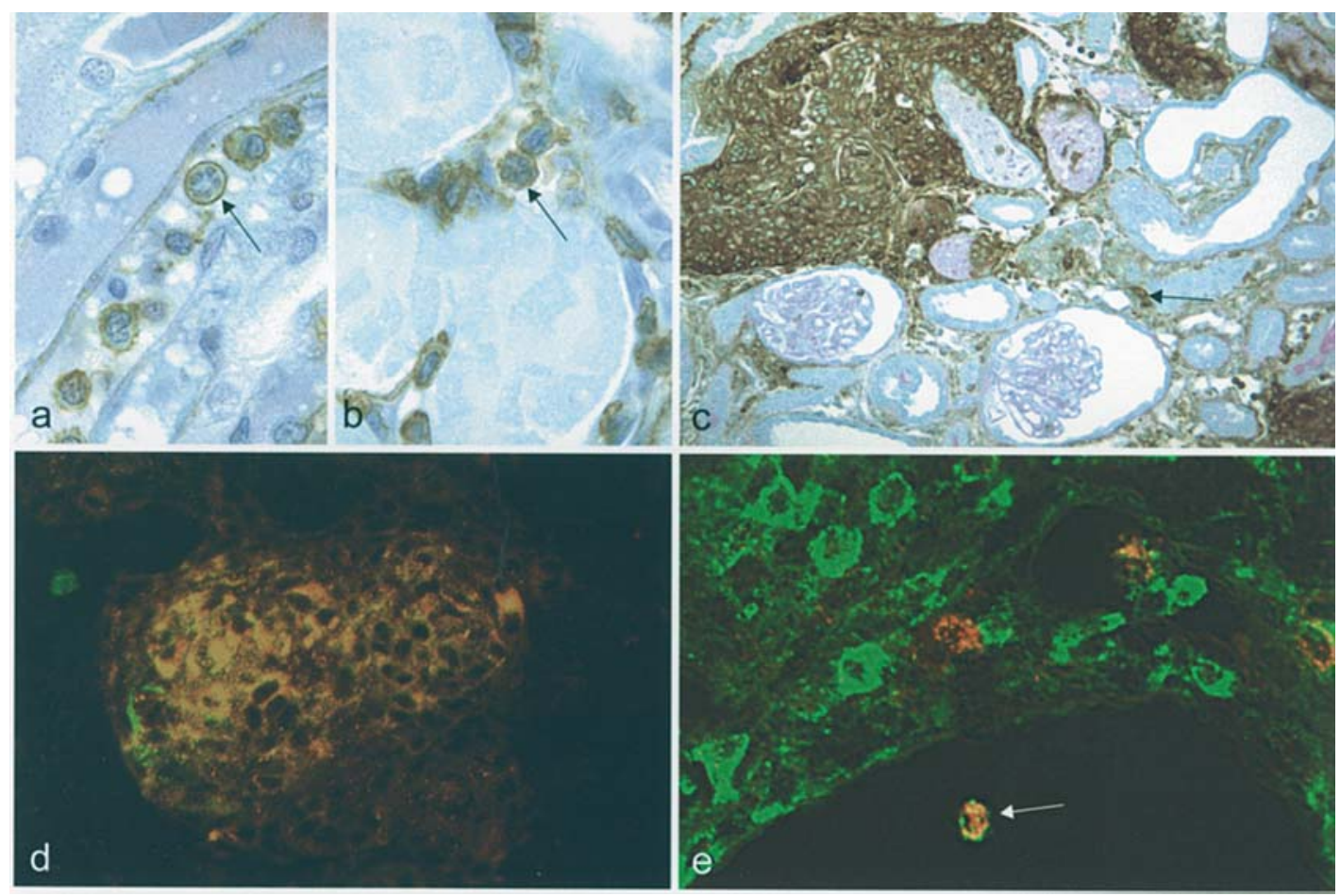

Figure 5. a-c: Immunoreactivity to CD44 (a, b, 48 h after reperfusion) and to ED1 (c, at 7 days). Neutrophilic granulocytes expressing CD44 were present in the lumen of blood vessels (a; arrow) and in the interstitium between necrotic tubules (b; arrow). A granuloma, densely immunostained with anti-ED1 (c), and isolated positive macrophages (arrow) were observed in the interstitium. d-e: Colocalization by double immunofluorescence of ED1 (red) and CD44 (green) in a granuloma (d) located in OSOM 7 days after ischemia and in a macrophage (e, arrow) in the lumen of a blood vessel of OSOM. As shown in e, numerous interstitial cells not identified as macrophages expressed CD44. Magnifications: a, b, x740; c, x140; d, x400; e, x650.

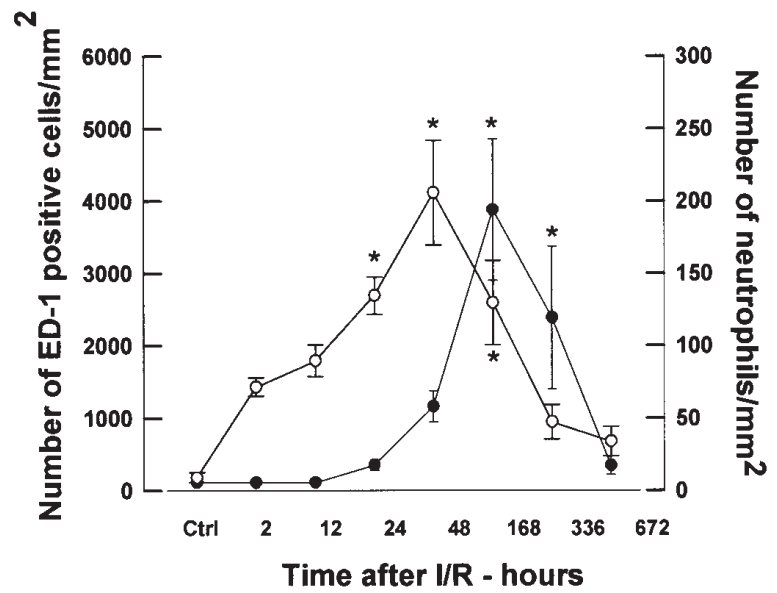

Figure 6. Temporal evolution of the number of ED1-positive cells (black circles) and neutrophils (open circles) present in both cortex and OSOM, in controls (Ctrl) and at different time-points after I/R. Statistical analysis was performed with a one-way ANOVA for multiple intergroup comparisons followed by the Dunnett's test to identify significant differences from the control group; ${ }^{*} \mathrm{p}<0.05$.

$(24 \pm 3 \%)$ but was largely devoid of CD44 expression. We observed a low and transient increase in HA around day 7, but no significant fluctuation in CD44 in postischemic IM.

Localization and quantification of leukocytes. Appropriate histological methods were used to differentiate neutrophils, mast cells, and monocytes/macrophages (ED1-positive cells collectively named macrophages). No mast cells were observed at any time-point in either control or post-I/R kidneys.

The presence of neutrophils within blood vessels and their infiltration into the interstitial tissue were noted as soon as $2 \mathrm{~h}$ after I/R in all kidney zones except IM (Fig. 5a and b). The time course of leukocyte invasion and recess in the interstitium of cortex and OSOM is illustrated in Fig. 6. A similar pattern was observed in ISOM but IM was less affected, since neutrophils appeared in IM at $12 \mathrm{~h}$ and had completely vanished by day 14. In absolute terms, neutrophil influx peaked in cortex and OSOM at $48 \mathrm{~h}$ and significant populations of neutrophils were still present at day 28. An overwhelming majority of infiltrating neutrophils in all zones was CD44-positive (Fig. 5a and $b)$.

Fig. 6 also illustrates the time-course of macrophage infiltration in the interstitium of cortex and OSOM. Macrophages appeared later than neutrophils, being first detected in OSOM at $24 \mathrm{~h}$ and extending to cortex and ISOM at $48 \mathrm{~h}$. They were much more numerous than neutrophils and reached peak values $\left(4000\right.$ cells $\left./ \mathrm{mm}^{2}\right)$ higher than those of neutrophils (200 cells $/ \mathrm{mm}^{2}$ ). Thereafter, the number of macrophages decreased slowly. Some of them aggregated in large granulomas and persisted for long periods, especially in cortex and OSOM (Fig. 5c). A few macrophages infiltrated IM between $48 \mathrm{~h}$ and day 14. Colocalization of ED1 and CD44 revealed that, in contrast to neutrophils, only $\sim 30 \%$ of macrophages were CD44-positive regardless of their distribution in interstitium (Fig. 5e) or in granulomas (Fig. 5d) and regardless of recovery time. 


\section{Discussion}

The renal I/R model used in the current study (60-min clamp of the left renal artery followed by contralateral nephrectomy) induced a severe but reversible acute renal failure. This model was characterized by a 10 -fold increase in plasma creatinine concentration on the second day of reperfusion and an almost complete return to baseline by day 14 . As evidenced by the histological lesions, this renal failure resulted from an acute tubular necrosis while glomeruli remained unaffected. Most of the recovery occurred during the first week after $I / R$, as attested by the presence of PCNA-positive, proliferative cells in tubular and interstitial structures. However, a minor population of cystic tubules associated with inflammatory granulomas was still present in the cortex and medulla 28 days after injury. This suggests that the initial injury induced chronic damages to the kidney despite normalization of plasma creatinine, as already observed by other investigators using the same rat model $(5,6)$. The whole situation is akin to renal transplantation which is frequently accompanied by a persistent inflammation characterized by phagocyte infiltration and cytokine release $(1,23)$. It is thus imperative to analyze all components of the early and mid-term recovery processes following severe I/R, including HA and CD44, in view of the possible consequences for long-term graft survival.

Hyaluronan. Normal rat kidneys contain almost no HA in cortex, apart from a fine mesh surrounding vessels. The association of HA and vascular smooth muscle cells has been demonstrated previously and HA and its binding proteins are known to play significant roles in arterial atherogenesis (24). In control rats, small amounts of HA were detected in the interstitium of OSOM and ISOM while a high density of interstitial HA was a characteristic of IM. The presence of HA in the inner medulla of the kidney suggests that this space-filling, waterretaining, and force-transducing polysaccharide could play a still undefined role in urinary concentration (25). The amount of HA in IM is lower during dehydration than during hydration $(26,27)$. In this study, we have observed that I/R injury does not significantly modify the amount of HA in IM and that IM is quite insensitive to the ischemic insult since very few lesions or inflammatory cells were observed at that deep level of the kidney. We may speculate that the large amounts of highmolecular weight HA in IM under baseline conditions (26) could exercise a protective effect against I/R-induced lesions by limiting the emission and/or the consequences of proinflammatory signals (28).

The expression of HA in the outer medulla and cortex after $\mathrm{I} / \mathrm{R}$ injury was more variable than in IM. Starting between 2 and $12 \mathrm{~h}$ post-I/R, and extending thereafter, HA progressively filled the interstitium of cortex and outer medulla. Since tissue leukocytes were already numerous $2 \mathrm{~h}$ after reperfusion, we conclude that deposition of HA in the renal interstitium is not a prerequisite for early leukocyte infiltration, in contrast to HA expression on endothelium and blood leukocytes, which represents a critical mechanism for the recruitment of neutrophils by the inflamed kidney (29).

HA was not detected between tubular cells within epithelia, suggesting that most of the synthesis emanates from interstitial cells, as suggested previously (30). However, recently, tubular cells have also been shown to synthesize HA and to secrete it through their apical side (31).

Our results support those of previous investigators who have described large depositions of HA in the renal cortex 3 days post-I/R (11), resulting from a specific increase of HAsynthase- 2 expression (32). In a bilateral I/R model, the percentage of interstitial HA-positive areas peaked at day 3 and decreased thereafter (29). In contrast to these observations, we have shown that a more severe $\mathrm{I} / \mathrm{R}$ insult to a single kidney results in a huge accumulation of interstitial HA in cortex and OSOM that persists between days 7 and 14 before slowly decreasing. At day 28 significant amounts of HA remained visible, particularly in OSOM and in close association with clusters of inflammatory cells, mostly macrophages. While the initial tide of HA appeared homogeneous in cortex and OSOM, the return to a normal appearance was more progressive and was characterized by persisting spots of interstitial HA in remodeling and regenerating areas. Similar observations have been made in experimental glomerulonephritis (8). This suggests that HA is involved in persistent renal inflammation following severe injuries and in chronic allograft nephropathy.

Conversely, extracellular HA could also be involved in the migration of regenerative cells, reminiscent of its role during morphogenesis (33), or it could interact with various growth factors inducing either regeneration or fibrosis. Experiments designed to remove HA or prevent its accumulation are needed to resolve these questions.

We have also shown that ISOM accumulated HA during the course of I/R recovery, although to a lesser extent than cortex or OSOM. The moderate increase of HA observed in ISOM was preceded by a transient decrease at day 1 . This could be due either to a specific inhibition of HA synthases at that particular location and time or to the activation of a degradation mechanism. This latter explanation is consistent with the fact that leukocytes penetrate ISOM rapidly after I/R (17) and could induce bursts of reactive oxygen species known to depolymerize HA (34). Furthermore, many activated leucocytes are trapped in congested microvascular vessels of ISOM and could either stimulate inflammation-related hyaluronidases or secrete their own hyaluronidases directly into the tissues (35). The causes and functions of the temporary washout of HA in ISOM one day after I/R remain to be investigated.

CD44. Our study has shown that the expression of CD44 was not linked to the expression of HA, either before or after injury. In control rats, CD44 was not only detected on the basal membrane of the majority of cells in the collecting ducts in ISOM, but also focally on collecting duct cells in OSOM and cortex. There, the interstitial tissue adjacent to CD44-positive collecting duct cells was generally devoid of HA staining. This suggests that other factors and ligands, such as osteopontin (36), control the functions of tubular CD44. This receptor also extends along the basal plasma membrane of the thin descending limb of Henle's loop and in the macula densa, suggesting possible specific activations of these segments. Jun et al (8) have reported that the baseline tubular CD44 expression was higher in medullary than in cortical tubules although other investigators did not observe immunoreactive CD44 in kidney tubules of control rats or mice $(12,29,37)$. The fact that we and others have been able to detect tubular CD44 
under baseline conditions may be due to a higher sensitivity of the immunohistochemical technique. Additionally, a few cells in Bowman's capsule and in the interstitium were also stained for CD44, confirming previous observations $(9,29)$.

Following I/R injury, we observed a striking increase of CD44 expression in both tubular and interstitial cells, especially during the first week. A majority of tubular cells were CD44positive even in proximal tubules where positive cells were sparse in control rats. Upregulation of plasma membrane molecules after the ischemic insult was not a universal feature of injured tubules since the expression of AQP-3, normally confined to the basolateral membrane of collecting ducts, decreased after I/R as reported previously by Kwon et al (38). Moreover, CD44 immunostaining extended to the apical membrane of tubular cells, yielding images of cells surrounded by a strong peripheral staining, while AQP-3 staining remained limited to the basolateral membrane. Cells with strongly enhanced CD44 expression seemed to correspond either to altered cells in cystic tubules or to regenerating tubules.

Morphometry has shown that the peak of CD44 staining was slightly delayed by comparison with the incidence of PCNA-positive regenerative cells, but the time-courses were difficult to interpret since CD44 was expressed on both resident kidney and inflammatory cells. In proximal tubules, CD44 was detected on all cells until they recovered normal morphological features and CD44 and brush border expressions appeared mutually exclusive, suggesting a transient role for CD44 in cell recovery, immediately after the proliferative phase but before final differentiation. This role is still speculative although it is possible that specific isoforms of CD44 could promote resistance to apoptosis $(14,39)$. CD44 is also overexpressed by postichemic resident interstitial cells, including fibroblasts for which a similar role could be postulated.

$\mathrm{I} / \mathrm{R}$ injury induced strong de novo apical membrane expression of CD44 in tubular cells in addition to the basolateral staining, as shown by the use of an antibody raised against the extracellular domain. Xie et al (40) have recently shown that a form of CD44 devoid of cytoplasmic tail was specifically expressed in regenerative proximal tubule cells consecutive to a gentamicin-induced acute tubular necrosis, whereas the standard form of CD44 was restricted to the basolateral membrane and to normal tubular cell polarity. It seems reasonable to suggest that a similar phenomenon occurs in the I/R model after acute tubular necrosis. A comparable polarized expression of CD44 was recently confirmed in a renal epithelial cell line (31).

During early nephrogenesis, it has been established that the HA-CD44 association promotes the formation and branching of the ureteric tree (39). However, the study of CD44-knockout mice subjected to mild bilateral I/R revealed that tubular regeneration was not altered and that kidneys recovered normal physiological functions (29). In other models, the absence of CD44 worsened tubular injury consecutive to ureteral obstruction (37) or lung injury after bleomycin administration (15). A possible explanation is that CD44 is required for the early penetration of circulating neutrophils into inflammatory areas leading to transient damage, but CD44 could also be needed for the secondary removal of HA from the injured tissues $(15,29,41)$.
Our observations confirmed the association of CD44 and inflammatory cells, not only within vascular lumens but also in the interstitial space. In cortex and medulla, a large majority of infiltrating neutrophils were CD44-positive throughout the observation period and could already be detected in the interstitium $2 \mathrm{~h}$ after reperfusion in all kidney zones except IM. The expression of CD44 by neutrophils could be related to their penetration into the tissue $(29,41)$, their migration through the interstitium (42), their binding to damaged cells or to extracellular fibers including HA-rich cable-like structures (43), or even their removal from the tissue $(29,41)$. The distribution and time-course of CD44 immunoreactivity observed in our experiments did not allow a deeper study of these aspects since the bulk of CD44 reactivity was related to epithelial cells and phagocytes.

Monocytes/macrophages were abundant in postischemic kidneys and, in agreement with previous observations (18), appeared later than neutrophils in particular within OSOM, the zone predominantly affected by I/R. Macrophages that remained present for longer periods than neutrophils have been suspected to support the repair process but also the late development of fibrosis (3). However, recent studies stress the critical role of macrophages in mediating the full extent of injury after I/R $(44,45)$, probably in coordination with $\mathrm{T}$ cells and neutrophils. In our study, less than half of the macrophages expressed detectable CD44 and no correlation could be established between the expression of CD44 and the distribution of macrophages within cortex and medulla. The observation that most tissue macrophages were not positive for CD44 may indicate that CD44 has been shed as part of their activity in the response to $\mathrm{I} / \mathrm{R}$, either through the activation of $\gamma$-secretase by cytokines (46) or though the action of metalloproteinases as repeatedly observed in cancer cells. The implications of such an event should be explored further.

In conclusion, the time-courses of HA and CD44 involvement up to 28 days after renal I/R are complex and probably underline a variety of functions of these partners. The accumulation of interstitial HA in cortex and outer medulla during the first two weeks after injury does not seem involved in early leukocyte infiltration, but it modifies the physicochemical environment of the interstitial cells and could participate in the migration of inflammatory and regenerative cells and in the persistence of tissue inflammation and subsequent fibrosis. This will be examined further. The HA receptor CD44 is present on the basal membranes of tubular cells; during recovery of $\mathrm{I} / \mathrm{R}, \mathrm{CD} 44$ is highly upregulated and extends to the apical membrane. It is closely associated with the regenerative phase but not the final differentiation of tubules. Infiltrating neutrophils are uniformly positive for CD44; besides determining the early access of neutrophils to the tissue, this expression of CD44 could correlate with their binding to stressed cells and their persistence in inflammatory pockets. On the other hand, most tissue macrophages were not positive for CD44. This means that CD44 may have been shed from phagocytic cells during their response to I/R.

\section{Acknowledgements}

This study received financial support from the Belgian Fund for Medical Scientific Research (Grants 3.4605.99 and 3.4583.01). 
Anne-Emilie Declèves is the recipient of a fellowship from FRIA (Fund for Research in Industry and Agriculture). The expert technical assistance of B. Blairon, F. Coulon, V. Jenart, A. Maes and J. Noël was greatly appreciated. We also thank Dr S. Nielsen (Water and Salt Research Center, University of Aarhus, Denmark) for the generous gift of AQP-3 antibody and Dr F. Gulbis for biochemical measurements. The results were presented in part at the 37th Annual Meeting of the American Society of Nephrology in St. Louis, USA, on October 27-November 1, 2004 (J Am Soc Nephrol 15: abs. 716, 2004), and at the 'Journées Takis Anagnostopoulos', in Paris, on June 16-17, 2005.

\section{References}

1. Tilney NL and Guttmann RD: Effects of initial ischemia/ reperfusion injury on the transplanted kidney. Transplantation 64: 945-947, 1997.

2. Bonventre JV and Weinberg JM: Recent advances in the pathophysiology of ischemic acute renal failure. J Am Soc Nephrol 14: $2199-2210,2003$.

3. Friedewald JJ and Rabb H: Inflammatory cells in ischemic acute renal failure. Kidney Int 66: 486-490, 2004.

4. Kelly KJ, Williams WW Jr, Colvin RB, Meehan SM, Springer TA, Gutiérrez-Ramos JC and Bonventre JV: Intercellular adhesion molecule-1-deficient mice are protected against ischemic renal injury. J Clin Invest 97: 1056-1063, 1996.

5. Basile DP, Donohoe D, Roethe K and Osborn JL: Renal ischemic injury results in permanent damage to peritubular capillaries and influences long-term function. Am J Physiol Renal Physiol 281: F887-F899, 2001.

6. Forbes JM, Heurtson TD, Becker GJ and Jones CL: Ischemic acute renal failure: long term histology of cell and matrix changes in rat. Kidney Int 57: 2375-2385, 2000.

7. Cruzado JM, Torras J, Riera M, Herrero I, Hueso M, Espinosa L, Condom E, Lloberas N, Bover J, Alsina J and Grinyo JM: Influence of nephron mass in development of chronic renal failure after prolonged warm renal ischemia. Am J Physiol Renal Physiol 27: F259-F269, 2000.

8. Jun Z, Hill PA, Lan HY, Foti R, Mu W, Atkins RC and Nikolic-Paterson DJ: CD44 and hyaluronan expression in the development of experimental crescentic glomerulonephritis. Clin Exp Immunol 108: 69-77, 1997.

9. Asselman M, Verhulst A, De Broe ME and Verkoelen CF: Calcium oxalate crystal adherence to hyaluronan-, osteopontin-, and CD44-expressing injured/regenerating tubular epithelial cells in rat kidneys. J Am Soc Nephrol 14: 3155-3166, 2003.

10. Wells A, Larsson E, Hanas E, Laurent T, Hällgren R and Tufveson G: Increased hyaluronan in acutely rejecting human kidney grafts. Transplantation 55: 1346-1349, 1993.

11. Johnsson C, Tufveson G, Wahlberg J and Hällgren R: Experimentally-induced warm renal ischemia induces cortical accumulation of hyaluronan in the kidney. Kidney Int 50: 1224-1229, 1996.

12. Lewington AJ, Padanilam BJ, Martin DR and Hammerman MR: Expression of CD44 in kidney after acute ischemic injury in rats. Am J Physiol Regul Integr Comp Physiol 278: R247-R254, 2000.

13. De Grendele HC, Estess P and Siegelman MH: Requirement for CD44 in activated $\mathrm{T}$ cell extravasation into an inflammatory site. Science 278: 672-675, 1997.

14. McKallip RJ, Fisher M, Gunthert U, Szakal AK, Nagarkatti PS, and Nagarkatti M: Role of CD44 and its v7 isoform in staphylococcal enterotoxin B-induced toxic shock: CD44 defiency on hepatic mononuclear cells leads to reduced activation-induced apoptosis that results in increased liver damage. Infect Immun 73: 50-61, 2005.

15. Teder P, Vandivier RW, Jiang D, Liang J, Cohn L, Puré E, Henson PM and Noble PW: Resolution of lung inflammation by CD44. Science 296: 155-158, 2002.

16. Thadhani R, Pascual M and Bonventre JV: Acute renal failure. N Engl J Med 334: 1448-1460, 1996.

17. De Greef KE, Ysebaert DK, Persy V, Vercauteren SR and De Broe ME: ICAM-1 expression and leukocyte accumulation in inner stripe of outer medulla in early phase of ischemic compared to $\mathrm{HgCl} 2$-induced acute renal failure. Kidney Int 63: 1697-1707, 2003.
18. Ysebaert DK, De Greef KE, Vercauteren SR, Ghielli M, Verpooten GA, Eyskens EJ and De Broe ME: Identification and kinetics of leukocytes after severe ischaemia/reperfusion renal injury. Nephrol Dial Transplant 15: 1562-1574, 2000.

19. Van Cauwenberge A, Nonclercq D, Laurent G, Zanen J, Beckers JF, Alexandre H, Heuson-Stiennon JA and Toubeau G: Immunohistochemistry of the golden hamster pituitary during chronic administration of diethylstilbestrol: a quantitative anlysis using confocal laser scanning microscopy. Histochem Cell Biol 115: 169-178, 2001

20. Lan HY, Mu W, Nikolic-Paterson DJ and Atkins RC: A novel, simple, reliable, and sensitive method for multiple immunoenzyme staining: use of microwave oven heating to block antibody crossreactivity and retrieve antigens. J Histochem 43: 97-102, 1995.

21. Morin NJ, Laurent G, Nonclercq D, Heuson-Stienon JA, Toubeau G, Bergeron MG and Beauchamp D: Epidermal growth factor accelerates renal tissue repair in a model of gentamicin nephrotoxicity in rats. Am J Physiol Renal Physiol 263: F806-F811, 1992.

22. Wattiez R, Nonclercq D, Journé F, Toubeau G, Zanen J, Falmagne P and Heuson-Stiennon JA: Involvement of transforming growth factor- $\alpha$ and its receptor in a model of DES-induced renal carcinogenesis in the syrian hamster. Carcinogenesis 17: 1615-1622, 1996.

23. Burne-Taney MJ, Yokota N and Rabb H: Persitent renal and extrarenal immune changes after severe ischemic injury. Kidney Int 67: 1002-1009, 2005.

24. Evanko SP, Angelo JC and Wight TN: Formation of hyaluronanand versican-rich pericellular matrix is required for proliferation and migration of vascular smooth muscle cells. Arterioscler Thromb Vasc Biol 19: 1004-1013, 1999.

25. Knepper MA, Saidel GM, Hascall VC and Dwyer T: Concentration of solutes in renal inner medulla: interstitial hyaluronan as a mechano-osmotic transducer. Am J Physiol Renal Physiol 284: F433-F446, 2003.

26. Flamion B, Boel P, Kramp RA and Mertens-Strijthagen J: Separate regulation of hyaluronan in the kidney cortex and medulla. In: Hyaluronan. Kennedy JF (ed). Woodhead Publishing Ltd., Abington, Cambridge, 2002.

27. Hansell P, Göransson V, Odlind C, Gerdin B and Hällgren R: Hyaluronan content in the kidney in different states of body hydration. Kidney Int 58: 2061-2068, 2000.

28. Neuman A, Schinzel R, Palm D, Driederer P and Nünch G: High molecular weight hyaluronic acid inhibits advanced glycation endproduct-induced NF-kB activation and cytokine expression. FEBS Lett 453: 283-287, 1999.

29. Rouschop KM, Roelofs JJ, Claessen N, Da Costa Martins P, Zwaginga JJ, Pals ST, Weening JJ and Florquin S: Protection against renal ischemia reperfusion injury by CD44 disruption. $\mathrm{J}$ Am Soc Nephrol 16: 2034-2043, 2005.

30. Göransson V, Hansell P, Moss S, Alcorn D, Johnsson C, Hällgren R and Maric C: Renomedullary interstitial cells in culture; the osmolality and oxygen tension influence the extracellular amounts of hyaluronan and cellular expression of CD44. Matrix Biol 20: 129-136, 2001.

31. Asselman M, Verhulst A, Van Ballegooijen ES, Bangma $\mathrm{CH}$, Verkoelen CF and De Broe ME: Hyaluronan is apically secreted and expressed by proliferating or regenerating renal tubular cells. Kidney Int 68: 71-83, 2005.

32. Göransson V, Johnsson C, Jacobson A, Heldin P, Hällgren R and Hansell P: Renal hyaluronan accumulation and hyaluronan synthase expression after ischaemia-reperfusion injury in the rat. Nephrol Dial Transplant 19: 823-830, 2004.

33. Toole BP: Hyaluronan in morphogenesis. Semin Cell Dev Biol 12: 79-87, 2001

34. Moseley R, Waddington RJ and Embery G: Degradation of glycosaminoglycans by reactive oxygen species derived from stimulated polymorphonuclear leukocytes. Biochim Biophys Acta 1362: 221-231, 1997.

35. Girard N, Maingonnat C, Bertrand P, Tilly H, Vannier J-P and Delpech B: Human monocytes synthesize hyaluronidase. Br J Haematol 119: 199-203, 2002.

36. Xie Y, Sakatsume M, Nishi S, Narita I, Arakawa M and Gejyo F: Expression, roles, receptors, and regulation of osteopontin in the kidney. Kidney Int 60: 1645-1657, 2001.

37. Rouschop KM, Sewnath ME, Claessen N, Roelofs JJ, Hoedemaeker I, van der Neult R, Aten J, Pals ST, Weening JJ and Florquin S: CD44 deficiency increases tubular damage but reduces renal fibrosis in obstructive nephropathy. J Am Soc Nephrol 15: 674-686, 2004. 
38. Kwon TH, Frokiaer J, Fernandez-LLama P, Knepper MA and Nielsen S: Reduced abundance of aquaporins in rats with bilateral ischemia-induced acute renal failure: prevention by $\alpha-\mathrm{MSH}$. Am J Physiol Renal Physiol 277: F413-F427, 1999.

39. Pohl M, Sakurai H, Stuart RO and Nigam SK: Role of hyaluronan and CD44 in in vitro branching morphogenesis of ureteric bud cells. Dev Biol 224: 312-325, 2000.

40. Xie Y, Nishi S, Fukase S, Nakamura H, Chen X, Imai N, Sakatsume M, Saito A, Ueno M, Narita I, Yamamoto T and Gejyo F: Different type and localization of CD44 on surface membrane of regenerative renal tubular epithelial cells in vivo. Am J Nephrol 24: 188-197, 2004.

41. Khan AI, Kerfoot SM, Heit B, Liu L, Andonegui, Ruffell P, Johnson P and Kubes P: Role of CD44 and hyaluronan in neutrophil recruitment. J Immunol 173: 7594-7601, 2004.

42. Alstergren P, Zhu B, Glougauer M, Mak TW, Ellen RP and Sodek J: Polarization and directed migration of murine neutrophils is dependent on cell surface expression of CD44. Cell Immunol 231: 146-157, 2004.
43. Majors AK, Austin RC, De la Motte CA, Pyeritz RE, Hascall VC, Kessler SP, Sen G and Strong SA: Endoplasmic reticulum stress induces hyaluronan deposition and leukocyte adhesion. J Biol Chem 278: 47223-47231, 2003.

44. Day YJ, Huang L, Ye H, Linden J and Okusa MD: Renal ischemia-reperfusion injury and adenosine $2 \mathrm{~A}$ receptor-mediated tissue protection: role of macrophages. Am J Physiol Renal Physiol 288: F722-F731, 2005.

45. Persy VP, Verhulst A, Ysebaert DK, De Greef KE and De Broe ME: Reduced postischemic macrophage infiltration and interstitial fibrosis in osteopontin knockout mice. Kidney Int 63: 543-553, 2003.

46. Jutras J, Laplante A, Boulais J, Brunet S, Thinakaran G and Desjardins M: $\gamma$-Secretase is a functional component of phagosomes. J Biol Chem 280: 36310-36317, 2005. 